\title{
Are Voters Rational?
}

\section{Teemu Lyytikäinen ${ }^{\mathrm{a}}$ and Janne Tukiainen ${ }^{\mathrm{b}}$}

16 January 2019

\begin{abstract}
We test whether a voter's decision to cast a vote depends on its probability of affecting the election outcome. Using exogenous variation arising at population cutoffs determining council sizes in Finnish municipal elections, we show that larger council size increases both pivotal probabilities and turnout. These effects are statistically significant, fairly large and robust. Finally, we use a novel instrumental variables design to show that the jumps in the pivotal probabilities are the likely candidate for explaining the increase in turnout, rather than the other observed simultaneous jumps at the council size cutoffs. Moreover, our results indicate that turnout responds only to within-party pivotal probabilities, perhaps because they are more salient to the voters than the between-party ones.
\end{abstract}

Keywords: Local government elections; Instrumental variables; Rational voting; Regression discontinuity design.

JEL codes: C26, D72

\footnotetext{
${ }^{*}$ We thank Manuel Bagues, Yosef Bhatti, Matz Dahlberg, Jon Fiva, Ronny Freier, Stefano Gagliarducci, Essi Eerola, Rafael Hortala-Vallve, Ari Hyytinen, Mika Kortelainen, Valentino Larcinese, David Myatt, Benjamin Lauderdale, Giacomo Ponzetto, Tuukka Saarimaa and Marko Terviö for useful comments. Seminar participants at FEAAM, EPSA, HECER, Jyväskylä, RES and VATT contributed to very useful discussions. Niklas Jahnsson provided outstanding research assistance. The paper has been awarded the Essex Social Science Data Analysis Award 2013 "for the best paper providing an empirical test of a theoretical argument presented at the 2012 European Political Science Association conference in Berlin". Janne Tukiainen thanks the Emil Aaltonen Foundation, the Jenny and Antti Wihuri Foundation and the Yrjö Jahnsson Foundation for generous funding and STICERD at the London School of Economics and Political Science for hospitality.

${ }^{a}$ VATT Institute for Economic Research, Arkadiankatu 7, Helsinki, FI-00101, Finland; and London School of Economics, Spatial Economics Research Centre. Houghton Street, London WC2A 2AE, United Kingdom. Email: teemu.lyytikainen@,vatt.fi. Tel: +358295519431.

${ }^{\mathrm{b}}$ Corresponding author: Department of Government, London School of Economics and Political Science, Houghton Street, London WC2A 2AE, United Kingdom; and VATT Institute for Economic Research, Arkadiankatu 7, Helsinki, FI-00101, Finland. Email: janne.tukiainen@vatt.fi. Tel +358295519451.
} 


\section{Introduction}

The expected instrumental benefits of voting are often thought to be close to zero, because the probability that a vote has an effect on the election outcome is typically close to zero (e.g. Grofman 1993 and Blais 2000). Moreover, the act of voting incurs non-negligible costs such as the opportunity cost of time. Therefore, if voters are rational in the sense that they only vote when the benefits of voting exceed the costs, the turnout rates should be very low in most elections, and particularly so in large elections. ${ }^{1}$ Yet, we observe relatively high turnout rates across countries and various elections, and it is not clear that turnout responds to the closeness of elections (e.g., Grofman 1993). This voting paradox (Downs 1957) has long puzzled social scientists and continues to do so.

Various explanations for the paradox have been offered both within and outside the rational voting paradigm. A simple way to explain the empirical patterns of high turnout is to introduce an additional utility component by assuming that voters derive utility from the act of voting itself. This expressive component may include elements such as social identity, civic duty or social pressure (e.g., Schuessler 2000 and Wiese and Jong-A-Pin 2017). Indeed, there is convincing empirical evidence that such expressive motives matter (e.g., Gerber et al. 2008 and Funk 2010).

The purpose of our study is to analyze whether the instrumental components of the rational voting model also matter for the decision to vote or abstain. Empirical analysis of the relationship between turnout and how close the elections are is complicated due to standard endogeneity issues. In particular, reverse causality is an inherent issue in such studies,

\footnotetext{
${ }^{1}$ This hypothesis is, however, somewhat debated. Mulligan and Hunter (2003) and Gelman et al. (1998) find pivotal probabilities to be very small in various U.S. elections. However, the expected incremental benefit is not necessarily small if voters have social preferences (e.g. Edlin et al. 2007). Moreover, once aggregate uncertainty is introduced, also the pivotal probabilities are larger than usually thought (Myatt 2015).
} 
because pivotal probability, i.e., the probability that one vote chances the election outcome, depends on turnout. Moreover, numerous unobservable candidate, voter and constituency characteristics may influence both turnout and how close the election is. Furthermore, it is not always easy to measure the pivotal probabilities, especially in proportional representation (PR) elections. In this paper, we make some progress in addressing both the issues of measurement and causal inference, although we cannot claim to be conclusive.

To overcome these challenges for causal inference, we utilize a natural experiment to analyze if turnout increases when the probability of one vote making a difference increases exogenously. In our quasi-experiment, we utilize population discontinuities in Finnish local government elections to construct a regression discontinuity design (RDD). In Finland, municipal council size is an increasing step function of population. Essentially, we compare otherwise similar municipalities with different council sizes. The discontinuities are sizeable. Crossing a population threshold increases council size by $20-30$ percent, depending on the threshold. This design allows us to evaluate causal effects of council size on various political outcomes - a first step in our attempt to evaluate rational voting.

In an open-list PR system, pivotal events are relatively common. They can occur both between parties, i.e., situations where one abstaining voter could change the allocation of seats between parties by voting, and within parties, i.e., situations where one voter could change which of the party's candidates gets the last seat of the party. In this setting, an increase in the amount of seats leads to an increase in the probability of a vote being pivotal. The effect arises most importantly simply from the elections allocating the last seats with a smaller amount of votes and thus smaller margins both between and within parties. According to our bootstrap election simulations, crossing the threshold where council size increases, increases the probability of pivotal occurrence between parties for the average 
party on average by about $18 \%$ (from 1.7 times out of a hundred to 2.0 ) and the probability of pivotal occurrence for the last seat within parties for the average candidate increases on average by about $17 \%$ (from 2.4 times out of a hundred to 2.8 ).

In the absence of precise manipulation of the municipal population, the treatment of increasing the council size is almost as good as random near the population thresholds. Therefore, this setup provides a valid causal test for the effect of council size on turnout. We find that turnout is higher just above the council size thresholds than just below. This result is fairly robust to extensive validity and robustness checks.

The main caveat of our natural experiment design in making conclusions about rational voting from the council size effect is that pivotal probabilities are not the only things that change at the thresholds. On the contrary, the relationship between turnout and district magnitude can arise from many sources. From the voter perspective, council size affects also proportionality and hence potentially political efficacy, because voters may perceive that less votes are wasted (see e.g. Eggers 2015, Gallego et al. 2012, Karp and Banducci 2008). Also parties may respond to changes in political competition (i.e. closeness of elections in a more general sense that just one vote making a difference) and hence induce elite mobilization (Powell 1986, Cox 1999, Cox et al. 2016), which may be reflected in campaigning and candidate placement. We also observe that the number of candidates and some of their characteristics change at the discontinuities. ${ }^{2}$ Besides a further impact of more candidates on the pivotal probability (vote distribution may be flatter), this may also influence turnout due

\footnotetext{
${ }^{2}$ In Finland, the maximum allowed size of each party list is a deterministic function of a council's size (1.5 times the council size). Moreover, parties and potential candidates may respond to an increase in council size by presenting a longer list, even when the limit is not binding.
} 
to some expressive components. ${ }^{3}$ Since RDD identifies only the joint effect of all the events that take place at each threshold, we cannot be sure whether the voters react to the pivotal probabilities or to e.g. the number of candidates. Fortunately, we are able to analyze this question of causal channel in detail using a novel procedure.

Our test of rational voting involves three steps. First, we document the overall effect of council size on turnout. Second, we simulate the pivotal probabilities for each municipalityparty both within and between parties. There are many attempts in the literature that test for rational voting by correlating some measures of expected closeness of elections to turnout (see e.g. Geys 2006 for a survey). One fundamental issue with such studies is that the real pivotal probability is highly nonlinear in relation to typical closeness measures such as margin of victory and the relationship is context dependent, e.g. $1 \%$ vote share victory margin may be either very far or very near to one vote being decisive (Cox 1988). Moreover, closeness realizes after the elections, and thus, is affected by turnout (Cox 1988 and Matsusaka and Palda 1993). We address these measurement and timing issues by bootstrapping pivotal occurrences.

Finally, we use our measure of expected pivotal probability simultaneously with the other endogenous variables in an instrumental variables regression (IV), where the different thresholds are the instruments. We find that the number or quality of candidates has consistently no significant effect on turnout, but that the pivotal probability has a positive and significant effect. Moreover, we find that turnout responds only to the more salient withinparty pivotality but not at all to the - harder to calculate - between-party pivotality. These results also largely rule out proportionality and elite mobilization as explaining the turnout

\footnotetext{
${ }^{3}$ For example, in the spirit of spatial models of voting (e.g., Downs 1957), voters may find a better match for their preferences. Moreover, more candidates may mean more available information, which may decrease the costs of voting (e.g., Matsusaka 1995). More candidates could also imply more campaigning.
} 
response, because they are mainly between-party concerns and also relate to political competition in general rather than to the influence of a single voter. Nonetheless, we also subject our measures of pivotality, general closeness of elections and proportionality to a horse race and find that only pivotality affects turnout.

This approach of using multiple thresholds to uncover and quantify the causal channel at work at the thresholds in RDD is an applied methodological contribution. Previous approaches to disentangle multiple treatments from each other in RDD with multiple thresholds have included focusing only on such 'clean' thresholds which affect only one of the treatments (see e.g. Ferraz and Finan 2009) or using variation in treatment timing by combining RDD with a difference-in-differences analysis (so called difference-indiscontinuity approach as first coined by Grembi et al. 2016). ${ }^{4}$ We provide a new alternative that requires, first, in the case of, for example, two simultaneous treatments A and B, there to be some threshold(s) where treatment A has a large intensity (but treatment B only small) and some other threshold(s) were treatment B has a large intensity (but treatment A only small), and second, that there are at least as many thresholds as endogenous variables (simultaneous treatments). Therefore, we contribute to the emerging methodological literature on the analysis of multiple cutoffs RDD (Eggers et al. 2018, Cattaneo et al. 2016). However, as usual in attempting to uncover causal mechanisms (see, e.g., Imai et al. 2011), our approach requires some strong assumptions that we discuss later, but the key issue is that, when it comes to this analysis, we are back to observationally world. This implies that despite the fairly clear patterns in the data in favor of rational voting, this evidence should be taken merely as suggestive.

\footnotetext{
${ }^{4}$ See also a recent survey and critical review of studies using multiple population thresholds in RDD by Eggers et al. (2018) whose concerns we carefully address.
} 


\section{Theoretical framework and prior empirical evidence}

The classic rational voting model (e.g., Downs 1957 and Riker and Ordeshook 1968) can be derived from a choice tree, where the decision is between voting and not voting and the two outcomes under both alternatives are the preferred candidate (or party) getting elected or not. Standard utility comparisons lead to the following rule:

(1) $\quad Y=1(D+p B-C>0)$,

where $Y=1$ if voter votes and zero otherwise, 1 denotes an indicator function, $D$ denotes the outcome-independent utility from voting. This is the expressive component, which was not present in the original model by Downs (1957). $C$ is the cost of voting. $B$ is the benefit of preferred election outcome and $p=p_{1-} p_{2}$, where $p_{1}$ is the probability that the preferred candidate will get elected if the voter votes, and $\mathrm{p}_{2}$ if the voter does not vote. In this model, $p$ vanishes as the set of voters gets larger. Therefore, with positive $C$, only large $D$ can explain large turnout in large elections.

Obviously, the existence or importance of $D$ in the voting decision does not imply irrationality as such. The pure expressive (or irrational) utility model assumes that $p$ does not matter even if it is not very small. Therefore, the $p$ component is at the heart of the rationality in these models. At its simplest, the expressive utility voting model can be presented as

(2) $\quad Y=1(D>C)$.

This would imply that a statistical test based on the $p B$ component would be able to separate between the rational and expressive voting hypothesis. On the contrary, showing that voters respond to the costs of voting does not allow differentiating between rational and expressive models. 
However, the testing also has to account for the possible strategic behavior of voters. Since $p$ depends on how many of the other potential voters actually vote, the decision to vote is strategic. Even if $D=0$, one would expect some amount of turnout due to $p$ getting larger the fewer of the other potential voters turn out (see e.g. Palfrey and Rosenthal 1983 and 1985). If voters differ in $D$ or $C$, pure strategy equilibria exist that can be presented by threshold values in $(D-C)$. In that scenario, only voters with high $(D-C)$ participate. $^{5}$ Therefore, game theory models may result in very similar empirical predictions to the expressive models where all hinges on $D$. This makes testing for rationality difficult: High or low turnout alone is not sufficient to infer the correct voting model.

There are plenty of alternative explanations for voting behavior in the literature and we do not cover them all. Explanations include a behavioral explanation of voters inflating their individual p's (Riker and Ordeshook 1968), and group voting where individuals are ethically obliged to a group and groups coordinate (first mentioned by Harsanyi 1955, empirical evidence by Coate and Conlin 2002). In addition, uncertain voter models (e.g., Matsusaka 1995 and Feddersen and Pesendorfer 1996, 1999), where the costs of voting have an endogenous relationship with the information available to voters on candidates, have been found to be empirically relevant in explaining turnout (Degan and Merlo 2011).

We use a natural experiment to estimate the causal effect of $p$ on $Y$ at an aggregate level. Thus, this analysis does not explicitly allow us to distinguish between alternative theories where pivotal probabilities play a role such as individually rational model or group voting model. However, we do show evidence that rational behavior with respect to the likelihood of

\footnotetext{
${ }^{5}$ If all voters are identical, they play mixed strategy equilibrium that leads to some positive level of turnout that is decreasing in population. However, population characteristics seem to matter as to a large extent the same people vote in sequential elections (e.g., Matsusaka and Palda 1999). This implies that mixed strategies are not typically used.
} 
changing the election outcome is a significant driver of the decision to vote, thus ruling out pure expressive models where none of the voters respond to the closeness of elections.

This seems important as there are some views (e.g., Fiorina 1989, Green and Shapiro 1994 and Aldrich 1997) the paradox of voting is proof against rational choice theory in general, and thus, challenges many models in social sciences. While there are convincing theoretical counterarguments (e.g., Cox 1999 and Myatt 2015), causal empirical evidence of rational voting has largely been missing, likely because it is difficult to identify.

Many attempts to uncover the relation between $Y$ and $p$ have been made previously. The evidence is mixed. For example, Geys (2006) reports in a survey article that $69 \%$ of the reviewed articles support the rational voting hypothesis, i.e., turnout responds to closeness of the elections. Unfortunately, these results are partial correlations and reveal no causal results. Among many, Indridason (2008), and more recently, Arnold (2018) deal with some endogeneity issues by focusing on run-off elections. They find that turnout responds to the closeness of the elections. The main limitation of the run-off elections approach is that the first round election outcome is not exogenous either. In a structural econometric paradigm, Coate et al. (2008) find that turnout responses to closeness are consistent with the rational voting model, but the responses in the margins of victory are not.

Natural experiments have been used previously to analyze other aspects of voting behavior. Andersen et al. (2014) show by using simultaneous elections for different offices, that turnout responds to larger stakes (increasing $B$ ). While this can be seen as an indirect test of voters also responding to $p$, it is also possible that $B$ is also partly determining $D$. Funk (2010) studies implementation of postal voting in Switzerland. She finds that the effect of removing social pressure from voting decisions on turnout (decreasing $D$ ) was larger than the effect of 
reduction in voting costs (decrease in C), especially in small communities. Garmann (2017) shows that frequent elections lead to voter fatigue that decreases turnout. Fujiwara (2011), Lago (2012), Kawai and Watanabe (2013) and Saarimaa and Tukiainen (2016) provide evidence that some voters are strategic. Given that voter participates, the decision who to vote for accounts for the pivotal probability concerning electing different candidates. RDD has been applied widely in other political economy contexts. Recent applications include Redmond and Regan (2015) and Tukiainen et al. (2018).

\section{Institutional setting}

In Finnish local government elections, voters elect the municipal councils. These elections are very important for several reasons. First, municipalities are responsible for the majority of public services in Finland, including health care and primary education. The GDP share of municipality spending is roughly 18 percent. Second, the municipalities are not heavily regulated in how they collect their income and they can also independently decide how to provide many of the public services. For example, they can freely set the income tax rate, which is the largest revenue source. Third, municipal councils are the main seat of power in municipal decision-making. Compared with many other countries, mayors or city managers do not wield much power in Finland, nor are they elected but are rather civil servants chosen by the council. Fourth, in most municipalities the probability of a vote being pivotal is fairly high, due to a relatively high number of council seats per capita and other details of the election rule, such as the open-list property and a multi-party system. Therefore, the pivotal occurrence rate is substantial and quite high on average, even in larger municipalities. Thus, we are able to observe significant responses in pivotality to the exogenous variation in council size. 
Finland has a multi-party system. Currently, there are eight parties in the Finnish parliament and these parties also dominate municipal politics, but some local single-issue groups exist as well. For example, in the 2004 municipal elections the three largest parties received around 68 percent of the votes with roughly similar overall shares but with large variation in shares between municipalities. The municipal council is responsible for strategic and financial outlines and the main objectives of municipal activities. The council also chooses a municipal board which has a preparatory role somewhat similar to a government in parliament. However, an important difference is that the composition of the board is based directly on party shares in the council, i.e., each party in the council gets seats in the municipal board according to its share of council seats. Thus, there is no formal or official opposition in local politics. Party coalitions are rather formed case-by-case rather than being fixed over the council term. This is important, because the majority of votes for some party or coalition is not the only relevant dimension where a single vote could have a meaningful impact. Moreover, also the within-party composition of councilors has been shown to affect the policy outcomes in Finland (Hyytinen et al. 2018). Therefore, for the implemented policies, every seat potentially counts, both within and between parties.

The elections in our data were held in the October of 1996, 2000, 2004, 2008 and 2012. The Election Day was the same for all municipalities. No other issues are voted upon at the same time. This is important as simultaneous elections would complicate the analysis (Eggers et al. 2018). The councils are elected using an open-list system. Each voter gives a single vote to a single candidate. Voters cannot vote only for a party without selecting a candidate. Individual votes rank the candidates within the parties. Thus, there are potentially pivotal events within parties. The total number of votes for all of the given party's candidates determines the number of votes for the party. The seats are allocated between parties based on the D'Hondt 
comparison method. ${ }^{6}$ Therefore, there are also potentially pivotal events between parties. Each municipality has only one electoral district.

Council size is a step function of the municipality's population and it is determined by law. Table 1 shows the amount of municipalities in different population groups with different council sizes. In Table 1, we show this distribution only up to a population of 45,000 , because after that the data are not dense enough for RDD and are thus omitted from our analysis. The sample below 45,000 covers 92 percent of municipalities and 46 percent of the population. As can be seen from Table 1, council size in our data varies from 13 for some municipalities with a population of 2,000 or less, up to 51 for municipalities with a population of between 30,000 and 45,000 . This concave step function implies that there is large variation in the amount of council seats per capita.

Table 1. Population groups, council size and number of elections in data.

\begin{tabular}{lcc}
\hline Population & Council seats & N \\
\hline$\leq 2000$ & 17 (or 15 or 13) & 274 \\
$2001-4000$ & 21 & 465 \\
$4001-8000$ & 27 & 478 \\
$8001-15000$ & 35 & 307 \\
$15001-30000$ & 43 & 168 \\
$30001-45000$ & 51 & 55 \\
\hline
\end{tabular}

In the Finnish system, the maximum number of candidates per party is 1.5 times the number of available seats. This implies that we would expect to find discontinuities also in the number of candidates. However, in our data, the limit is binding (they field the maximum number of candidates) for only around $2 \%$ of parties. Be as it may, our empirical strategy is

\footnotetext{
${ }^{6}$ The candidates of each party in the municipality are ordered according to their votes and they are given comparison numbers calculated by dividing total votes for the party in the municipality first by 1 , then by 2 , then 3 etc. Council seats are allocated to the candidates with the highest comparison numbers.
} 
designed to separate between the different observable channels through which the population thresholds could affect turnout.

\section{Empirical strategy}

Our empirical approach consists of three steps. First, we estimate the impact of council size on turnout in local elections using regression discontinuity design. The second step is to measure the pivotal probability, i.e., the probability that one vote changes the outcome of the election. The third step is the analysis of mechanisms behind the overall effect of council size on turnout. To achieve this we outline a novel instrumental variables approach, where we use the discontinuities as instruments.

\subsection{Step 1: The effect of council size on turnout}

The basic idea of our empirical strategy is to compare turnout in municipalities below and above the cut-off points. The main identifying assumption in such RDD is that individuals cannot precisely manipulate the forcing variable (see e.g. Lee and Lemieux 2010). This should be true in our case, because municipalities do not self-report their population. In this case, identification is based on a local randomization at the threshold. ${ }^{7}$ Ideally, we would have many data points close to the threshold and then estimate the effect at the threshold. In our case, due to lack of observations and having multiple thresholds, we need to use specifications that use data points further away from the thresholds. More specifically, we estimate both parametric polynomial regressions and nonparametric local linear regressions. We prefer the parametric ones because they lend themselves more easily to the analysis with multiple thresholds and especially to our novel instrumental variable approach. However, we

\footnotetext{
${ }^{7}$ Local randomization is not a requirement but rather one possible interpretation of RDD. What is required is that potential outcomes develop smoothly over the threshold. One difference between these two perceptions is that the latter allows there to be trends in the other covariates. See Cattaneo et al. (2015) for further discussion.
} 
also show that in our particular case, the parametric specification produces similar results as the more flexible nonparametric approach. ${ }^{8}$

A further complication to our analysis is how to deal with multiple thresholds. One option would be to calculate the forcing variable as a population distance to the nearest threshold and simply define a single group for being above a threshold. We do not use this pooling option because we want to allow for different effects at different thresholds (see also Cattaneo et al. (2015) on the loss of information resulting from the pooling approach). This will be important in our instrumental variables method, where we have more than one endogenous variable. Therefore, we will estimate a model with the actual population as the forcing variable and then allow for a different effect at different thresholds. We will calculate the overall average effect as the weighted (by the number of observations around each threshold) average of these separate effects. Pooling also creates its own challenges for the validity of the design and testing for it (Eggers et al. 2018).

Our main specification is a parametric model where we simply fit polynomials of population of varying order over the whole range of population and include dummy variables for groups defined based on council size. We estimate by OLS the following equation

(3) Turnout $_{i t}=\beta_{1}+\beta_{2}$ Group $_{i t}+\ldots+\beta_{6}$ Group $_{i t}+f\left(\right.$ Pop $\left._{i t}\right)+u_{i t}$.

The dependent variable is the turnout in municipality $i$ in election year $t$. Function $f$ is a polynomial of population. We use $1^{\text {st }}-7^{\text {th }}$ order polynomials. The explanatory variables of interest are overlapping dummies Group2,..,Group6, indicating all municipalities above a certain threshold. For example, Group 2 includes all the municipalities with a population of

\footnotetext{
${ }^{8}$ In general, it is not advised to use parametric specifications, see e.g. Imbens and Gelman (2018) for the many issues with the parametric approach.
} 
more than $2,000 .{ }^{9}$ Our estimating sample contains data from the first six groups, because we limit the analysis to municipalities with a population of less than 45,000 to keep the data somewhat dense. This implies that the results may not necessarily be generalizable to bigger municipalities. However, pivotal events also occur in the excluded municipalities quite often. The respective group coefficients $\beta_{2, \ldots, \beta_{6}}$ give direct estimates of the effect on turnout of increasing council size by one step. The group dummies can be interpreted as individual treatment variables, with the previous group as the control group. Therefore, this specification allows for a different effect at each threshold.

Main drawback of the model in equation (3) is that it uses data far from the cut-offs to estimate the value of the polynomial at the cut-off. Therefore, we introduce more flexible models as robustness checks. We add both more flexible parametric specifications as well as standard nonparametric local polynomial regressions (Imbens and Kalyanaraman 2012 and Calonico et al. 2014). These specifications give very similar results as our main specification for each separate cutoff, and thus, we feel confident in using the less flexible parametric approach (3) as the main specification. See Online Appendix B for details.

One factor that could make observing an effect at the threshold more difficult is that a larger council may decrease turnout because power per councilor may be lower, thus the benefit of getting one's own candidate elected may be lower. Moreover, Eggers et al. (2018) have raised the concern that population thresholds may not provide clean identification, because in many countries municipalities' responsibilities, grants, politicians' salaries and regulation depend also on the same thresholds. In that case, there are simultaneous exogenous treatments and RDD is able to only identify their joint effect. None of these concerns is

\footnotetext{
${ }^{9}$ Non-overlapping dummies would produce the same fit of the model, but we prefer the overlapping dummies, because the related coefficients have directly our desired interpretation.
} 
present in the Finnish system. However, in addition to the number of seats, the maximum number of candidates allowed for each party also changes at the cut-offs. More candidates could affect turnout if people find it easier (or harder) to find a suitable candidate from a larger pool. Moreover, also candidate quality can respond to a change in council size. ${ }^{10}$ Finally, district magnitude also affects the closeness of elections more generally as well as the proportionality of the elections. In order to isolate the effect of pivotal probability from the other effects, we conduct an instrumental variables (IV) analysis that we describe in detail in Step $3 .^{11}$ Before we can proceed to IV, we need to be able to measure the pivotal probabilities.

\section{2. $\quad$ Step 2:Measuring pivotal probabilities}

We calculate the pivotal events both between parties, i.e., situations where one abstaining voter could change the allocation of seats between parties by voting, and within parties, i.e., situations where one voter could change which of the party's candidates gets the last seat of the party. A pivotal event takes place both in the case of actual draws (in which case a lottery would determine who gets elected) and also when giving one more vote creates a draw or a different seat allocation directly.

The basic idea of the simulation is that the sampling procedure allows us to mimic the randomness involved in voters' decisions on whether to vote at all and who to vote for. For example, changes in the weather, disease occurrence and travelling patterns may make a difference on which voters give their vote. Kotakorpi et al. (2017) develop the bootstrap sampling method that we use as a basis for our simulation. They use the method to define close elections. We modify the algorithm to calculate pivotal probabilities.

\footnotetext{
${ }^{10}$ See e.g., Cox (1997) or Fiva and Folke (2015) for analysis of strategic entry of candidates.

${ }^{11}$ Simply controlling for all the other things changing at the cutoffs is not satisfactory, because they are alternative response variables, and therefore 'bad controls'.
} 
We sample votes with replacement for each candidate, so that the sampling probability of a vote for a particular candidate is the share of all votes that he or she received in the real elections. We sample as many votes as were originally given in the real elections. Each sampling produces a new distribution of votes among the candidates, while on average maintaining the original distribution of votes. After each sample, we take note of a pivotal event after each repetition. We repeat this exercise 1,000 times and count the share of times a pivotal event occurred for each party-election (between parties) and each candidate-election (within parties) observation. Thus, this is a bootstrap procedure for a particular non-standard statistic of the vote distribution, the pivotal vote probability. The simulation produces almost continuous variables between zero and one that are good measures of the probability of a pivotal event between and within parties. We analyze the validity of this claim in graph A1 the Online Appendix A where we show that the simulated values predict very well the realized pivotal events. We also report that the simulated values seem to provide a monotonic transformation of the real pivotal occurrence that slightly underestimates the real occurrence.

We show in the Online Appendix A Tables A1 and A2 using counterfactual simulations that our measure works as intended and jumps at the cutoffs in the expected way, that is, it jumps much at the smaller thresholds and less at the larger. Besides showing that crossing the threshold has a significant impact on the pivotal probability, our simulations are essential in providing a metric that can be used to analyze whether the effect of council size on turnout is due to increases in pivotal probability at the thresholds or due to other changes at the threshold.

To get the metric that we use in the IV, we conduct a counterfactual simulation, where we construct measures of pivotal probabilities that do not include the effects of crossing the threshold on turnout. This counterfactual is needed to correctly measure the effect of crossing 
the threshold on expected pivotality at the first stage of IV. In other words, the counterfactual corrects for the bias arising from simultaneity between turnout and pivotality. We accomplish this by manipulating the turnout. We use equation (3) and regress turnout on $1-7^{\text {th }}$ order polynomials of population, election year dummies and the cut-off group dummies. Then we subtract from the resulting fit the effects of the group dummies on the fit. We use this adjusted fit as the counterfactual turnout that determines the number of votes given in our counterfactual simulations.

We stress that our measure of pivotality is not a measure of closeness of elections in any more general sense. We measure the incidence of cases where a single vote would make a difference. In contrast, simulated elections where, for example, 3 votes would make a difference to the seat allocation could be seen a close, but would not count as pivotal in our metric. We can also construct a simple metric for the more general closeness of elections, for example the victory margin. In the within-party dimension where votes rank the candidates, this is simply the distance in personal vote share to the within-party threshold of getting elected. In our IV estimation we can test whether the response in turnout is explained by this within-party margin of victory or by the within-party pivotality.

\subsection{Step 3:Identifying the causal mechanisms}

In our IV regression, we estimate the main RDD equation (3) in the first stage (see Online Appendix $\mathrm{C}$ for these first stages). The first endogenous variable (the first stage outcome) is the simulated counterfactual pivotal probability. As the second first stage outcome we use the (absolute) number of candidates and the share of incumbent candidates is the third. Incumbency status is an often used metric for candidate quality, because it typically 
correlates with the other observable candidate quality measures (Eggers et al. 2015). ${ }^{12}$ Therefore, it can potentially influence turnout. Moreover, we show that other observable candidate characteristics do not jump at the threshold (Table B8 in the Online Appendix). It also seems likely that the incumbency share jumps mechanically rather than as a behavioral response: There simply are more incumbents in larger councils. The fourth variable is the proportionality measured as the minimum vote share among the elected candidates in the municipality. There are other proportionality measures such as the Gallagher index. All the different proportionality measures aim to measure roughly the same thing and all that we have analyzed follow the same pattern. Therefore, it is sufficient to include only one to our IV. Other observables are shown not to jump at the threshold and therefore not considered endogenous (see Table B4, discussed later).

We conduct this estimation both at the election and election-party level. Therefore, we want to measure also pivotal probability at the election (or election-party) level. In order to achieve this aggregation, we take a weighted (by respective vote shares) average over both the withinparty pivotal probability (measured at the candidate level) and the between parties pivotal probability (measured at the party level) to calculate the probability that a randomly drawn voter would be pivotal in a given election. We use either a single measure for pivotality, which is simply the sum of these weighted between and within pivotalities, or both of them separately. These measures along with the other endogenous variables and the outcome variable turnout are described in Table 2 at both municipal and party level. For the pivotal probabilities we report the counterfactuals based on a $6^{\text {th }}$ order polynomial specification

\footnotetext{
${ }^{12}$ Eggers et al. (2015) show that in majoritarian systems many candidate characteristics differ between close winners and losers of elections, but these differences vanish once incumbency is controlled for, because incumbency status is so strongly correlated with the other measures.
} 
similar to equation (3). Differences to descriptions in Table A1 arise mainly from the weighting.

Table 2. Describing endogenous variables in $I V$.

\begin{tabular}{lccccc}
\multicolumn{1}{c}{ Variable } & $\mathrm{N}$ & Mean & Std. Dev. & Min & Max \\
\hline & \multicolumn{1}{c}{ Panel A: Election level } & & & \\
\hline Turnout & 1746 & 0.65 & 0.061 & 0.42 & 0.89 \\
Pivotality & 1746 & 0.063 & 0.031 & 0.006 & 0.193 \\
Number of candidates & 1746 & 84 & 48 & 14 & 305 \\
Share of incumbents & 1746 & 0.26 & 0.07 & 0.12 & 0.71 \\
Proportionality & 1746 & 0.014 & 0.007 & 0.002 & 0.052 \\
\hline & Panel B: Party-election level & & \\
\hline Pivotality, within & 10171 & 0.006 & 0.009 & 0.000 & 0.164 \\
Pivotality, between & 10171 & 0.020 & 0.020 & 0.000 & 0.130 \\
Number of candidates & 10171 & 14 & 13 & 1 & 76 \\
Share of incumbents & 10171 & 0.21 & 0.17 & 0 & 1 \\
Proportionality & 8656 & 0.018 & 0.011 & 0.002 & 0.158 \\
\hline
\end{tabular}

In the second stage, we use the fits of the first stages to explain turnout. In other words, we perform an IV regression of turnout on simulated pivotal probability, the number and type of candidates and proportionality using the threshold dummies as the excluded instruments. The estimation equations are written as

1st stage: Pivotality $_{i t}=\beta_{1}+\beta_{2}$ Group $_{i t}+\ldots+\beta_{3}$ Group $_{i t}+f\left(\right.$ Pop $\left._{i t}\right)+u_{i t}$.

1st stage: Nro of candidate $_{i t}=\delta_{1}+\delta_{2}$ Group $_{i t}+\ldots+\delta_{6}$ Group $_{i t}+f\left(\right.$ Pop $\left._{i t}\right)+v_{i t}$ 1st stage: Quality of candidates

$$
=\theta_{1}+\theta_{2} \text { Group }_{i t}+\ldots+\theta_{6} \text { Group }_{i t}+f\left(\text { Pop }_{i t}\right)+r_{i t}
$$

1st stage: Proportionality Prt $_{1}=\kappa_{1}+\kappa_{2}$ Group $_{i t}+\ldots+\kappa_{6}$ Group $_{i t}+f\left(\right.$ Pop $\left._{i t}\right)+k_{i t}$ 
2nd stage: Turnout ${ }_{i t}$

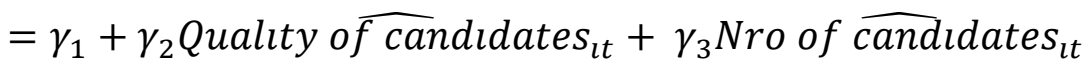

$$
\begin{aligned}
& +\gamma_{4} \text { Plvotallt }_{l t}+\gamma_{5} \text { Proportıonalıty }+f\left(\text { Pop }_{i t}\right)+e_{i t}
\end{aligned}
$$

Identification of our parameter of interest $\gamma_{4}$ requires the fairly strong assumption that all the relevant mechanisms that are correlated with pivotality and through which crossing the threshold can influence turnout are included in the model. Therefore, in this part of the analysis, we are in an observational world. However, despite substantial effort, we have not been able to find any confounding policies, other than the number of seats and candidates, using the same thresholds in Finland.

\section{Estimation results}

\subsection{The effect of council size on turnout}

We report the data sources and descriptive statistics in the Online Appendix D. Graph 1 illustrates our empirical strategy and data. The graph reports population bin averages of turnout in local elections and the fit of the equation (3) regression using on the $6^{\text {th }}$ order polynomial of population. The bin width varies somewhat based on the density of the data being 500 between 0 and 10000 population, 1000 between 10000 and 20000 and 2000 above that. The vertical lines indicate the cut-offs where council size increases. The regression line shows that turnout in municipal elections jumps up at all the five cut-offs, which indicates that council size increases turnout.

Graph 2 shows turnout in national parliamentary elections as a placebo test. These general elections take place one year prior to local elections and there pivotal probabilities are not affected by size of the municipality. For national elections, there is no uniform pattern in the shifts of the regression line. There is a downward shift at two cut-offs and an upward shift at 
three cut-offs. This suggests that the stepwise pattern in municipal election turnout is indeed driven by the discontinuities in council size and not by confounding factors affecting general propensity to vote. Interestingly, in Graph 1 we observe also that turnout decreases with population, as we would expect if voters are rationally responding to decreasing pivotal probability as population increases. For national elections in Graph 2, the relationship between population and turnout is flat. This is again natural as the national elections uses larger districts where municipal population plays no role and in which voters across the entire country have roughly similar influence. Therefore, already Graphs 1 and 2 provide difference-in-differences style evidence that response to population is different across these two elections and in line with rational behavior.

Graph 1. Average voter turnout in local elections by population group.

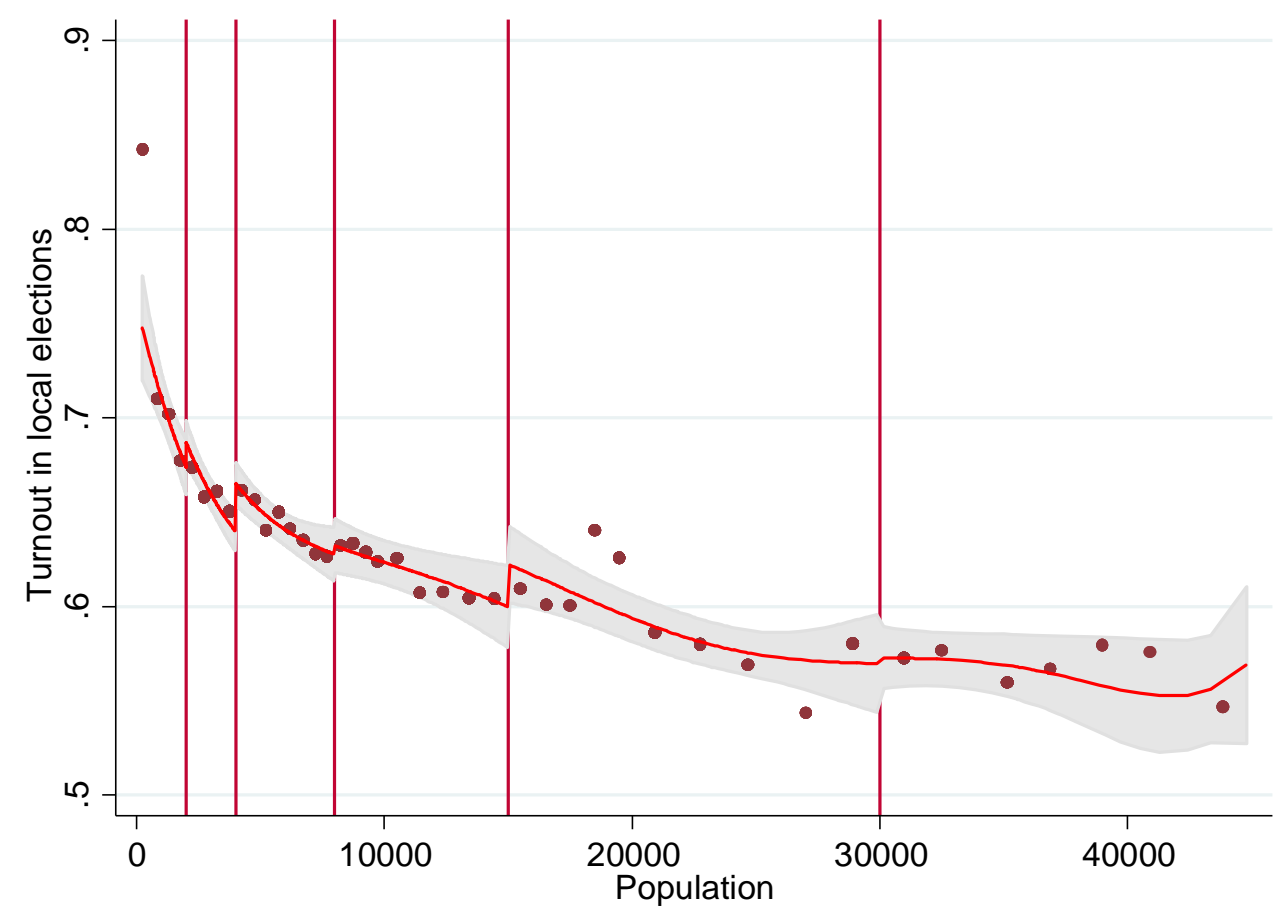


Graph 2. Placebo check: average voter turnout in national elections by population group.

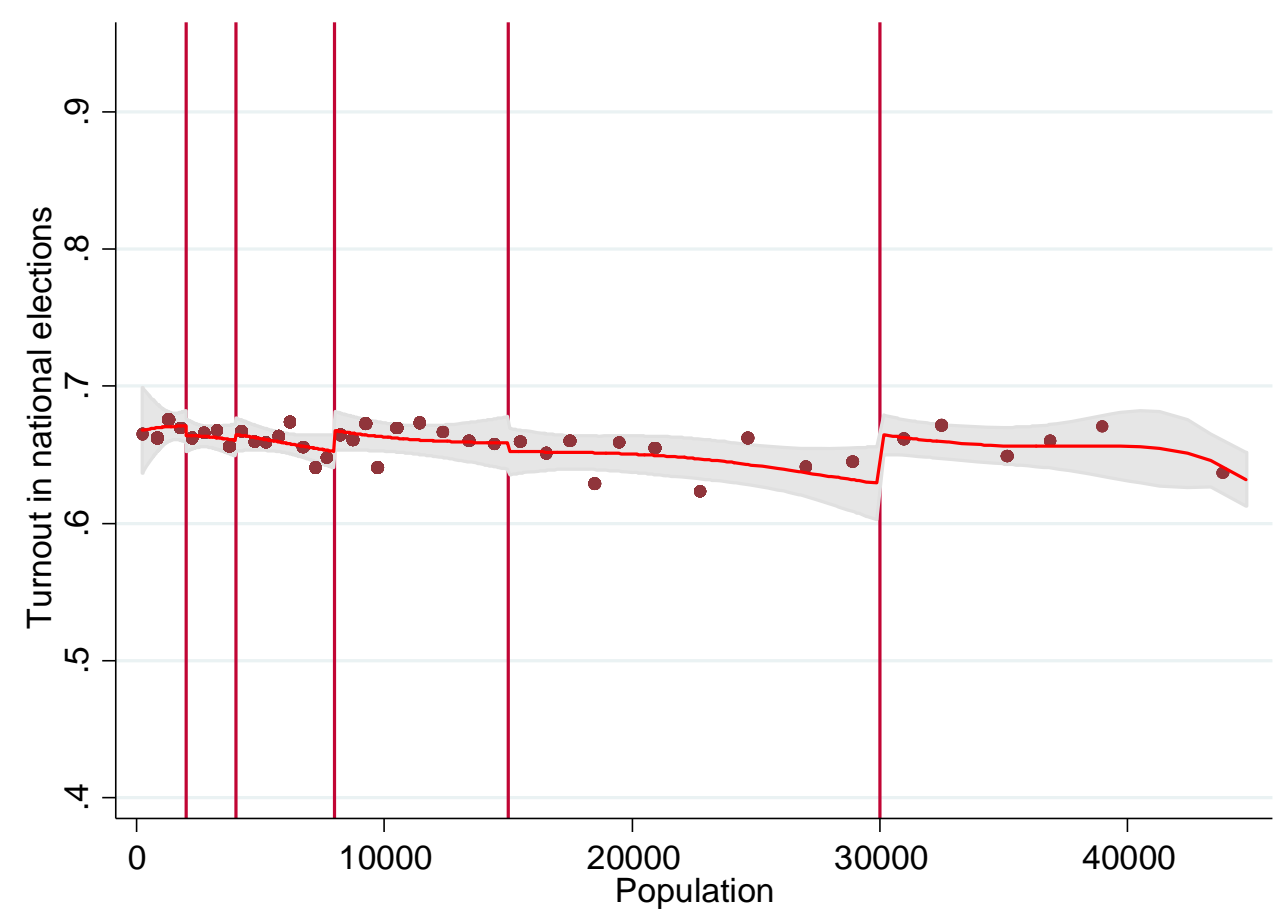

Table 3 reports the individual coefficients of the group dummies of equation 3 (individual cutoff treatment effects), as well as the weighted average treatment effect across the cutoffs. ${ }^{13}$ Columns $1-7$ use $1^{\text {st }}-7^{\text {th }}$ order polynomials of population. The group dummies indicate that turnout increases with council size at every threshold for most specifications, but the individual effects are typically not significant. However, the average effect of a one-step increase in council size is positive across the board and statistically significant and quite robust in the specifications with a third or higher order polynomial of population.

The estimates e.g. in the $6^{\text {th }}$ column implies that crossing a council size threshold increases turnout by 1.5 percentage points on average. It is not very easy to evaluate whether this effect

\footnotetext{
${ }^{13}$ Here the average effect is calculated as the weighted average of the effects at the individual cutoffs, where the weights are the numbers of observations around each respective cutoff.
} 
is small or large. It seems to be relatively small compared to the cross sectional variation across elections of similar size (see Graph 1). On the other hand, relatively large changes in population size would be required to achieve 1.5 percentage point change in turnout. For example, based on the model fit of the $6^{\text {th }}$ order polynomial model in Table 3 , in our data, a municipality with population size 7528 has a predicted turnout of $63 \%$ and a municipality with 5535 inhabitants has a fit of $64.5 \%$. Thus, the population needs to decrease by about 2000 (27\% decrease in population) to achieve 1.5 percentage points increase in turnout.

Table 3. Council size and voter turnout in municipal elections (equation (3) results).

\begin{tabular}{|c|c|c|c|c|c|c|c|}
\hline \multicolumn{8}{|c|}{ Dep var: Turnout in municipal elections } \\
\hline \multicolumn{8}{|c|}{ Order of polynomial of pop } \\
\hline Threshold & $1 \mathrm{st}$ & 2nd & 3rd & 4th & 5 th & 6th & 7 th \\
\hline \multirow[t]{2}{*}{ pop $>2 \mathrm{k}$} & $-0.025^{* * *}$ & $-0.016^{* *}$ & -0.01 & 0.001 & 0.008 & 0.013 & 0.015 \\
\hline & {$[0.007]$} & {$[0.008]$} & {$[0.008]$} & {$[0.009]$} & {$[0.010]$} & {$[0.011]$} & {$[0.012]$} \\
\hline \multirow[t]{2}{*}{ pop $>4 \mathrm{k}$} & -0.002 & 0.011 & $0.019^{* *}$ & $0.027 * * *$ & $0.028 * * *$ & $0.026 * * *$ & $0.023 * *$ \\
\hline & {$[0.006]$} & {$[0.007]$} & {$[0.008]$} & {$[0.009]$} & {$[0.009]$} & {$[0.009]$} & {$[0.009]$} \\
\hline \multirow[t]{2}{*}{ pop $>8 \mathrm{k}$} & 0.001 & $0.018^{*}$ & $0.022^{* *}$ & 0.016 & 0.009 & 0.005 & 0.005 \\
\hline & {$[0.008]$} & {$[0.010]$} & {$[0.010]$} & {$[0.010]$} & {$[0.011]$} & {$[0.012]$} & {$[0.012]$} \\
\hline \multirow[t]{2}{*}{ pop $>15 \mathrm{k}$} & $0.025^{* *}$ & $0.036^{* * *}$ & $0.025^{*}$ & 0.007 & 0.010 & 0.023 & 0.023 \\
\hline & {$[0.012]$} & {$[0.014]$} & {$[0.014]$} & {$[0.016]$} & {$[0.016]$} & {$[0.018]$} & {$[0.018]$} \\
\hline \multirow[t]{2}{*}{ pop $>30 \mathrm{k}$} & $0.048 * * *$ & 0.005 & 0.001 & $0.033^{*}$ & 0.013 & 0.003 & 0.018 \\
\hline & {$[0.014]$} & {$[0.013]$} & {$[0.014]$} & {$[0.018]$} & {$[0.015]$} & {$[0.017]$} & {$[0.019]$} \\
\hline \multirow[t]{2}{*}{ Average effect } & 0.001 & $0.010^{*}$ & $0.013^{* *}$ & $0.016^{* * *}$ & $0.015^{* *}$ & $0.015^{* *}$ & $0.016^{* * *}$ \\
\hline & {$[0.005]$} & {$[0.006]$} & {$[0.006]$} & {$[0.006]$} & {$[0.006]$} & {$[0.006]$} & {$[0.006]$} \\
\hline
\end{tabular}

Notes: Sample size is 1,747. Standard errors are in brackets (clustered at municipality level). Significance is denoted by asterisks: $* \mathrm{p}<0.1, * * \mathrm{p}<0.05, * * * \mathrm{p}<0.01$.

We conduct a large battery of additional analyses to evaluate the robustness and validity of these results. These are reported in the Online Appendix B. First, the main drawback of our main specification (equation 3) is that it is quite inflexible, and thus, uses data far from the 
cut-offs to estimate the function $f$ at the cut-offs. ${ }^{14}$ We address this by estimating much more flexible specifications both by increasing the flexibility of the parametric specification, and importantly, using state-of-the-art nonparametric local polynomial methods. The results are quite robust. They are also robust to adding a rich set of control variables.

Second, we also test the validity of the RDD through two placebo tests. First, we use data on turnout in national parliamentary elections to see if the overall propensity to vote is correlated with the treatment variables. We confirm the findings in Graph 2 also in regression analysis. In our second placebo test, we estimate equation (3) with artificial cut-offs created by shifting the real cut-offs between $-40 \%$ and $40 \%$. The pattern is as it should be.

Manipulation and precise control over population measures would invalidate the research design. In our setup, the manipulation of population statistics would be very costly to municipalities, because this information is gathered independently by central government from the official population register. Furthermore, as is standard in the literature, we conduct a McCrary (2008) density test of manipulation separately for each threshold. We do not find evidence of manipulation at any of the five analyzed thresholds.

Finally, we test for the possibility that the results might be driven by confounding factors not adequately captured by the polynomial of the population by using a rich set of background characteristics of municipalities and candidates as well as measures of political competition as the dependent variables in the RDD. All these variables are balanced supporting the validity of the RDD.

\footnotetext{
${ }^{14}$ Note that while we use up to $7^{\text {th }}$ order polynomial of population, which seems quite flexible, we do not allow the coefficients relating to this to change across the cutoffs in equation (3). This makes that model quite inflexible in comparison to usual RDD practices.
} 


\subsection{Causal mechanims}

The purpose of the IV regressions is to compare which of the possible channels explains the effect of council size on turnout. The studied mechanisms are voters responding either to pivotal probabilities, number of candidates or their quality, or proportionality. In the Online Appendix C, we report the results from the four first stages of our IV regression using municipal level analysis. All the four variables seem to be relevant based on the significance of the average effects. Moreover, the individual thresholds seem to affect different outcomes somewhat differently, implying that the second stage regression may identify which of these mechanisms is behind the overall effect. Note also that the overall effect is strongest at the second threshold which is also significant for all the endogenous variables (at least in most specifications) implying that more than one mechanism may be behind the overall findings. The $\mathrm{F}$ tests tell that the first stage for proportionality is the strongest, for the pivotal probability the second strongest, but for the two candidate variables quite weak.

We report the municipality level second stage results in Table 4 . We limit the analysis to $3^{\text {rd }}$ to $6^{\text {th }}$ order polynomials. ${ }^{15}$ The municipal level analysis is not able to identify separately which mechanism explains the increase in turnout. This is reflected both in the insignificant parameter estimates and in the under-identification test. The endogenous variables are too collinear and the instruments too weak to tell apart the mechanisms.

\footnotetext{
${ }^{15}$ We do not use the $1^{\text {st }}-2^{\text {nd }}$ order, because the overall effect of council size on turnout was not present then. We do not use $7^{\text {th }}$ or higher order, because the first stage $\mathrm{F}$ tests show that the first stages of all the endogenous variables become less powerful as the order of polynomial increase (see Online Appendix C).
} 
Table 4. The effects of pivotal probability, proportionality, number of candidates and share of incumbent candidates on turnout in municipal elections, IV estimates, second stage, municipal level.

\begin{tabular}{lcccc}
\hline \multicolumn{5}{l}{ Dep var: Turnout in municipal elections } \\
\hline \multicolumn{5}{c}{ Order of polynomial of pop } \\
Threshold & 3rd & 4th & $5^{\text {th }}$ & 6th \\
\hline Candidates & 0.0008 & 0.0020 & 0.0021 & 0.0016 \\
& {$[0.0005]$} & {$[0.0018]$} & {$[0.0013]$} & {$[0.0010]$} \\
Share of incumbents & 0.2931 & 1.4252 & 1.0438 & 0.6756 \\
& {$[0.9151]$} & {$[2.2870]$} & {$[1.2642]$} & {$[0.4687]$} \\
Proportionality & 1.0208 & 3.5453 & 5.8762 & 7.0097 \\
& {$[3.3208]$} & {$[5.9947]$} & {$[6.1793]$} & {$[5.7116]$} \\
Pivotal probability & 0.3308 & -3.8488 & -1.9451 & 0.6344 \\
& {$[2.7858]$} & {$[7.3934]$} & {$[4.0780]$} & {$[1.9726]$} \\
\hline Kleibergen-Paap under- & & & & \\
identification test & 0.998 & 0.349 & 0.719 & 2.47 \\
p-value & 0.607 & 0.84 & 0.698 & 0.29 \\
\hline \hline
\end{tabular}

Notes: Sample size is 1,746. Standard errors are in brackets (clustered at municipality level). Significance is denoted by asterisks: $* \mathrm{p}<0.1, * * \mathrm{p}<0.05, * * * \mathrm{p}<0.01$.

In Online Appendix C, we report the first stage results at the municipality-party level rather than the municipality level. This increases the number of observations from 1746 to 10171 . For each party, we calculate the party level turnout (the share of eligible voters voting for a particular party), the absolute number of candidates, the share of incumbent candidates and the pivotal probabilities both within the party and between the respective party and other parties, as well as the party proportionality as the vote share of the last elected candidate in the party. ${ }^{16}$ We also ask whether the political competition variable (the margin of victory within party) jumps at the threshold in the party-level data even though it did not in the municipal level analysis.

Both the between- and within-party pivotality jump at the thresholds and in roughly similar pattern. All the other four variables seem to be also relevant based on the significance of the

\footnotetext{
${ }^{16}$ In Finland, all eligible voters are automatically registered. Residents who are 18 or older by the election date are eligible.
} 
average effects. Moreover, the individual thresholds seem to affect different outcomes somewhat differently, implying that the second stage regression may identify which of these mechanisms is behind the overall effect.

We begin the municipality-party level second stage analysis by asking how turnout responds to the between- and within-party pivotality in Table 5. The result is striking: Turnout responds only to the within-party pivotal probabilities but not at all to the between-party ones. The within-party effect is large, robust and highly significant. The between-party effect is negative but not significant. According to the under-identification test in Table 5, the effects are separately identified despite the variables being correlated.

We argue that a likely explanation for this is that the within-party dimension is much more salient. Within parties the election system is simply $N$ past the post, where $N$ refers to the number seats for the given party. The pivotal calculus is much simpler within party than between party, because it depends only on the votes given to members of that single party, and thus, voters can easily observe how many votes decided the elections at the margin of getting elected last time (pivotal probabilities are highly correlated over time) ${ }^{17}$. On the contrary, between-party pivotal calculus requires information on the votes to all the parties and understanding and calculating of the fairly complex D'Hondt election mathematics. However, an alternative possible explanation is that within party dimension of political selection is more important for the voters.

\footnotetext{
${ }^{17}$ Autocorrelation of the within party pivotal probability with lagged pivotality is 0.55 and similarly 0.43 for the between party pivotal probability, and both are highly significant.
} 
Table 5. The effects of between- and within-party pivotal probability on turnout, IV estimates, second stage, party level.

\begin{tabular}{lcccc}
\hline \multicolumn{5}{l}{ Dep var: Turnout in municipal elections } \\
\hline \multicolumn{5}{c}{ Order of polynomial of pop } \\
& 3rd & 4th & 5th & 6th \\
\hline Between-party pivotality & -0.773 & -0.971 & -1.282 & -1.282 \\
& {$[0.897]$} & {$[0.833]$} & {$[0.898]$} & {$[0.898]$} \\
Within-party pivotality & $7.638^{* * *}$ & $8.045^{* * *}$ & $8.169^{* * *}$ & $8.169^{* * *}$ \\
& {$[1.680]$} & {$[1.504]$} & {$[1.493]$} & {$[1.493]$} \\
\hline Kleibergen-Paap under- & \multicolumn{4}{c}{} \\
identification test & 8.84 & 11.8 & 12.1 & 12.9 \\
p-value & 0.065 & 0.019 & 0.016 & 0.012 \\
\hline \hline
\end{tabular}

Notes: Unit of observation is party-election $(\mathrm{N}=10,171)$. Only municipalities with a population below 45,000 are included. Standard errors are in brackets (clustered at municipality level). Significance is denoted by asterisks: $* \mathrm{p}<0.1, * * \mathrm{p}<0.05, * * *$ $\mathrm{p}<0.01$.

There may naturally be omitted variables explanations for why within-party pivotality seems to be a more important driver of the turnout response than between-party pivotality. One potential explanation for the results in Table 5 is that within-party pivotality is correlated with some other mechanism that is really behind the turnout response, whereas between-party pivotality is not. We turn to this in Table 6 where the within-party pivotality is analyzed jointly with the other endogenous variables. We find evidence that the most plausible channel of crossing the threshold on turnout is the pivotal probability, because it has a large, positive and significant effect in three out of four specifications and the other endogenous variables are not significant in any specification. Moreover, the under-identification tests suggest that for the $3^{\text {rd }}$ order polynomial specification we are likely to be able to identify all the five effects separately. In Table C11 in the Appendix C, we also show that the result for pivotality are robust to including only one of the other endogenous variable at the time as well including these variables as squared to assure that nonlinearities in the effects of the other endogenous variables are not important. 
Table 6. The effects of pivotal probability, number of candidates and share of incumbent candidates on turnout in municipal elections, IV estimates, second stage, party level.

\begin{tabular}{lcccc}
\hline \multicolumn{5}{c}{ Dep var: Party turnout in municipal elections } \\
& \multicolumn{5}{c}{ Order of polynomial of pop } \\
& 3rd & 4th & 5 th & 6th \\
\hline Candidates & 0.000 & 0.004 & 0.003 & -0.002 \\
& {$[0.001]$} & {$[0.005]$} & {$[0.005]$} & {$[0.014]$} \\
Share of incumbents & -0.122 & -0.189 & -0.357 & -1.025 \\
& {$[0.152]$} & {$[0.202]$} & {$[0.711]$} & {$[3.515]$} \\
Proportionality & -0.106 & -5.252 & -8.217 & -7.85 \\
& {$[2.762]$} & {$[9.620]$} & {$[23.199]$} & {$[33.170]$} \\
Political competition & 2.506 & 32.713 & 44.582 & 11.071 \\
& {$[15.312]$} & {$[55.905]$} & {$[115.388]$} & {$[63.428]$} \\
Within-party pivotality & $6.017^{* * *}$ & $6.578^{* * *}$ & $7.098^{* *}$ & 4.725 \\
& {$[1.592]$} & {$[2.166]$} & {$[3.458]$} & {$[7.142]$} \\
\hline Kleibergen-Paap under- & \multicolumn{4}{c}{} \\
identification test & 4.42 & 0.737 & 0.274 & 0.128 \\
p-value & 0.035 & 0.39 & 0.60 & 0.72 \\
\hline \hline
\end{tabular}

Notes: Unit of observation is party-election $(\mathrm{N}=8384)$. Party list with none elected are excluded. Only municipalities with population below 45,000 are included. Standard errors are in brackets (clustered at the municipality level). Significance is denoted by asterisks: $* \mathrm{p}<0.1, * * \mathrm{p}<0.05, * * * \mathrm{p}<0.01$.

It is hard to come up with possible omitted alternative mechanism than the ones already included in Table 6. For example any behavioral responses by the parties or the candidates, for example increased campaigning effort in the municipalities just above the threshold, should be captured by the included variables. Parties and candidates should respond to the political competition variable rather than the pivotality variable, because they can influence more than one voter simultaneously. Moreover, both this results and the fact that turnout only responds to the within-party dimension largely rules out a role of elite mobilization.

While the presented IV evidence is fairly robust and strong in favor of at least some voters behaving in a rational way, we have to bear in mind that these results arise from fairly inflexible first stage RDD specifications, implying that some identification may come from data points somewhat away from the cutoffs and/or from the functional form. Adding more flexibility is difficult for both technical (we do not know how to implement nonparametric 
$\mathrm{RDD}$ as first stages in our IV procedure) and practical reasons (IV is much more data intensive than RDD, and thus, adding more flexibility to the parametric first stages results in noisy estimates).

\section{Conclusions}

We present quasi-experimental evidence that is consistent with the rational voting hypothesis. We use RDD to show that turnout increases when the number of available council seats in elections increases exogenously. We also use election simulations to show that the change in seats increases the probability of one single vote having an impact on the election outcome. This change is sharp and relatively large at the discontinuity. We also use a novel instrumental variables design utilizing the presence of multiple thresholds to show that the effect on turnout can more likely be attributed to the increase in pivotal probability rather than to the simultaneous increase in the number of candidates, the candidates' quality, proportionality or political completion more generally. The voters seem to conduct calculus of voting and take this into account when making decisions on whether to vote or to abstain.

Our results do not imply that the expressive utility components would not also matter. Moreover, our results cannot rule out some of the alternative explanations for pure rational voting such as group voting where larger groups consider their pivotality together. We can only state that the calculus of voting seems to also matter. It may also be the case that only some voters but not all conduct the calculus of voting. Moreover, we do not learn much concerning how exact or heuristic this calculus is, for example it may well be that voters learn about pivotal probabilities from the results of the past elections rather than actually

calculating them. We can only say that whatever type of calculus is conducted, it is empirically consistent with the rational voting model in Finnish municipal elections. Despite 
these limitations, this is an important finding as the rational choice theory has been critically assessed by many (e.g., Aldrich 1997, Schuessler 2000 and Green and Shapiro 1994).

The Finnish proportional open-list election system has features of both majority and closedlist elections, since the within-party competition component is simply N-past-the-post and the between parties competition component is the same as in the closed-list proportional system. Therefore, the results can potentially apply to a wide range of other institutions and countries. Of particular interest here is that voters seem only to respond to the within-party pivotal probabilities but not to the between-party ones. This result has potential implications for the generalizability of the results. One should expect to see rational voting under simple election rules such as first-past-the-post or majority elections, but less likely in more complex systems such as closed-list proportional elections.

The only interest of this study is not what mechanism voters respond to but also what mechanisms they do not respond to. It is interesting to observe that the possible increase in political efficacy due to proportionality effects are not likely to be behind the turnout results, nor are elite mobilization or other party or candidate responses. Finally, it is important to point out that we showed that increasing district magnitude had many different effects as there were responses in turnout, pivotal probabilities, candidate quantity and quality, and intensity of competition and proportionality. Researchers interested in studying the effects of district magnitude should take care to account for all these channels. We have provided one method to address this simultaneity issue.

\section{References}

Andersen J, Fiva J, Natvik G (2014). Voting When the Stakes Are High. Journal of Public Economics 110, 157-166. 
Aldrich J (1997). When is it Rational to Vote? In Perspectives on Public Choice, A Handbook, pp.379-390. Mueller D (ed.), Cambridge University Press.

Arnold F (2018). Turnout and Closeness: Evidence from 60 Years of Bavarian Mayoral Elections. The Scandinavian Journal of Economics 120, 624-653.

Blais A (2000). To Vote or Not to Vote: The Merits and Limits of Rational Choice Theory. University of Pittsburg Press.

Calonico S, Cattaneo M and Titiunik R (2014), "Robust nonparametric confidence intervals for regression-discontinuity designs.” Econometrica 82, 2295-2326.

Cattaneo M, Frandsen B, Titiunik R. (2015). Randomization Inference in the Regression Discontinuity Design: An Application to Party Advantages in the U.S. Senate. Journal of Causal Inference 3, 1-24.

Cattaneo M, Keele L, Titiunik R and Vazquez-Bare G (2016). Interpreting Regression Discontinuity Designs with Multiple Cutoffs. Journal of Politics 78, 1229-1248.

Coate S, Conlin M (2002). A Group Rule-Utilitarian Approach to Voter Turnout: Theory and Evidence. American Economic Review 94, 1476-1504.

Coate S, Conlin M, Moro A (2008). The Performance of Pivotal-voter Model in Small-scale Elections: Evidence from Texas Liquor Referenda. Journal of Public Economics 92, 582-596.

Cox G (1988). Closeness and Turnout: A Methodological Note. The Journal of Politics 50, $768-775$.

Cox G (1997). Making Votes Count: Strategic Coordination in the World's Electoral Systems. Cambridge University Press. 
Cox G (1999). The Empirical Content of Rational Choice Theory: A Reply to Green and Shapiro. Journal of Theoretical Politics 11, 147-169.

Cox G (1999). Electoral Rules and the Calculus of Mobilization. Legislative Studies Quarterly 24, 387-420.

Cox G, Fiva J, Smith D (2016). The Contraction Effect: How Proportional Representation Affects Mobilization and Turnout. The Journal of Politics 78, 1249-1263.

Degan A, Merlo A (2011). A Structural Model of Turnout and Voting in Multiple Elections. Journal of the European Economic Association 9, 209-245.

Downs A (1957). An economic theory of democracy. Harper and Row, New York.

Edlin A, Gelman A, Kaplan N (2007). Voting as a Rational Choice: Why and How People Vote to Improve the Well-Being of Others. Rationality and Society 19, 293-314.

Eggers A (2015). Proportionality and Turnout: Evidence from French Municipalities, Comparative Political Studies 48, 135-167.

Eggers, A, Fowler A, Hainmueller J, Hall A, Snyder J (2015). On the Validity of the Regression Discontinuity Design for Estimating Electoral Effects: New Evidence from Over 40,000 Close Races. American Journal of Political Science 59, 259-274.

Eggers A, Freier R, Grembi V and Nannicini T (2018). Regression Discontinuity Designs Based on Population Thresholds: Pitfalls and Solutions. American Journal of Political Science 62, 210-229.

Feddersen T, Pesendorfer W (1996). The Swing Voter's Curse. American Economic Review $86,408-424$. 
Feddersen T, Pesendorfer W (1999). Abstention in Elections with Asymmetric Information and Diverse Preferences. American Political Science Review 93, 381-398.

Ferraz C, Finan F (2009). Motivating Politicians: The Impacts of Monetary Incentives on Quality and Performance. NBER Working Paper No. 14906.

http://www.nber.org/papers/w14906.pdf.

Fiorina M (1989). Retrospective Voting in American National Elections. New Haven: Yale University Press.

Fiva J, Folke O (2016). Mechanical and Psychological Effects of Electoral Reform. British Journal of Political Science 46, 265-279.

Fujiwara T (2011). A Regression Discontinuity Test of Strategic Voting and Duverger's Law. Quarterly Journal of Political Science 6, 197-233.

Funk P (2010). Social Incentives and Voter Turnout: Evidence from the Swiss Mail Ballot System. Journal of the European Economic Association 8, 1077-1103.

Gallego A, Rico G, Anduiza E (2012). Disproportionality and Voter Turnout in New and Old Democracies. Electoral Studies 31, 159-169.

Garmann S (2017). Election Frequency, Choice Fatigue, and Voter Turnout. European Journal of Political Economy 47, 19-35.

Gelman A, King G, Boscardin J (1998). Estimating the Probability of Events That Have Never Occurred: When Is Your Vote Decisive? Journal of the American Statistical Association 93, 1-9. 
Gelman A, Imbens G (2018). Why Higher Order Polynomials Should not be Used in Regression Discontinuity Designs. Journal of Business \& Economic Statistics (forthcoming).

Gerber A, Green, D, Larimer, C (2008). Social Pressure and Voter Turnout: Evidence from a Large-Scale Field Experiment. American Political Science Review 102, 33-48.

Geys B (2006). Explaining Voter Turnout: A Review of Aggregate Level Research. Electoral Studies 25, 637-663.

Green D, Shapiro I (1994). Pathologies of Rational Choice Theory: A Critique of Applications in Political Science. Yale University Press.

Grembi V, Nannicini T, Troiano U (2016). Do Fiscal Rules Matter? American Economic Journal: Applied Economics 8, 1-30.

Grofman B (1993). Is Turnout the Paradox that Ate the Rational Choice Theory? In Information, Participation, and Choice: An Economic Theory of Democracy in Perspective, Grofman B (ed.), 93-103, University of Michigan Press.

Harsanyi J (1955). Cardinal Welfare, Individualistic Ethics, and Interpersonal Comparisons of Utility. Journal of Political Economy 63, 309-321.

Hyytinen A, Meriläinen J, Saarimaa T, Toivanen O, Tukiainen J (2018). Public Employees as Politicians: Evidence from Close Elections. American Political Science Review 112, 1, 6881.

Imai K, Keele L, Tingley D, Yamamoto T (2011). Unpacking the Black Box of Causality: Learning about Causal Mechanisms from Experimental and Observational Studies. American Political Science Review 105, 765-789. 
Imbens G, Kalyanaraman K. (2012). Optimal Bandwidth Choice for the Regression Discontinuity Estimator. Review of Economic Studies 79, 933-59.

Indridason I (2008). Competition \& Turnout: The Majority Run-Offs as a Natural Experiment. Electoral Studies 27, 699-710.

Karp J and Banducci S (2008). Political Efficacy and Participation in twenty-seven Democracies: How Electoral systems Shape Political Behaviour. British Journal of Political Science 38, 311-334.

Kawai K, Watanabe Y. (2013). Inferring Strategic Voting. American Economic Review 103, $624-662$.

Kotakorpi K, Poutvaara P, Terviö M (2017). Returns to Office in National and Local Politics: A Bootstrap Method and Evidence from Finland. Journal of Law, Economics, \& Organization 33, 413-442.

Lago I (2012). Strategic Voting in Proportional Representation Systems: Evidence from a Natural Experiment. Party Politics 18, 653-665.

Lee D, Lemieux T (2010). Regression Discontinuity Designs in Economics. Journal of Economic Literature 48, 281-355.

McCrary J (2008). Manipulation of the Running Variable in the Regression Discontinuity Design: A Density Test. Journal of Econometrics 142, 968-714.

Myatt D (2015). A Theory of Voter Turnout. London Business School mimeo. http://dpmyatt.org/uploads/turnout-2015.pdf. 
Matsusaka J (1995). Explaining Voter Turnout Patterns: An Information Theory. Public Choice 84, 91-117.

Matsusaka J, Palda F (1993). The Downsian Voter Meets the Ecological Fallacy. Public Choice 77, 855-878.

Matsusaka J, Palda F (1999). Voter Turnout: How Much Can We Explain? Public Choice 98, 431-446.

Mulligan C, Hunter C (2003). The Empirical Frequency of a Pivotal Vote. Public Choice 116, $31-54$.

Palfrey T, Rosenthal H (1983). The Strategic Calculus of Voting. Public Choice 41, 7-53.

Palfrey T, Rosenthal H (1985). Voter Participation and Strategic Uncertainty. American Political Science Review 79, 62-78.

Powell Jr. G (1986). American Voter Turnout in Comparative Perspective. The American Political Science Review 80, 17-43.

Redmond P, Regan J (2015). Incumbency Advantage in a Proportional Election System: A Regression Discontinuity Analysis of Irish Elections. European Journal of Political Economy 38, 244-256.

Riker W, Ordeshook P (1968). A Theory of the Calculus of Voting. American Political Science Review 62, 25-42.

Saarimaa T, Tukiainen J (2016). Local Representation and Strategic Voting: Evidence from Electoral Boundary Reforms. European Journal of Political Economy 41, 31-45.

Schuessler A (2000). A Logic of Expressive Voting. Princeton University Press. 
Tukiainen J, Takalo T, Hulkkonen T (2018). Relative Age Effects in Political Selection. European Journal of Political Economy (forthcoming).

Wiese R, Jong-A-Pin R (2017). Expressive Voting and Political Ideology in a Laboratory Democracy. European Journal of Political Economy 50, 54-74. 